\title{
Rechazo deseoso: la música y el resentimiento desde la vida dañada
}

Desiring rejection: music and resentment from damaged life.

Jéssica Raquel Rodeguero Stefanuto

Universidade Estadual Paulista “Julio de Mesquita Filho" - UNESP - Marília/SP, Brasil.. Fundação Educacional de Penápolis - FUNEPE -Penápolis/SP, Brasil. jessicaraquelpsi@yahoo.com.br

DOI: http://doi.org/10.15366/bp2019.21.008

Bajo Palabra. II Época. No21. Pgs: 147-158 
El presente trabajo fue realizado con apoyo de la Coordinación de Perfeccionamiento de Personas de Nivel Superior - Brasil (CAPES) - Código de Financiación 001.

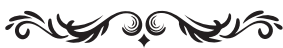

\section{Resumen}

El objetivo de este texto es discutir la siguiente hipótesis: en el contexto de la vida dañada, las canciones con pretensión de autonomía, que acogen las contradicciones y lo no idéntico y que, por lo tanto, tienen potencial de crítica y formación humana, afectan a los oyentes y son capaces de producir rechazo. Desde la Teoría Crítica de la Sociedad, se discute que el rechazo es también deseoso, pues que somos muy violentamente privados de formación. Así, se concluye que la vida dańada construye una relación de resentimiento entre los oyentes y la música con pretensiones de autonomía, lo cual se pone como peligroso frente a las pocas posibilidades de formación que todavía permanecen en las contradicciones.

Palabras Clave: Resentimiento; Filosofia de la Música; Formación; Teoría Crítica.

\section{Abstract}

This text aims to discuss the following hypothesis: in the context of damaged life, songs with a claim to autonomy, which accept contradictions and what is not identi$\mathrm{cal}$ and that, therefore, have the potential for criticism and human formation affect the listeners and are capable of producing rejection. From the Critical Theory of the Society, it is argued that the rejection is also desirous, because we are very violently deprived of formation. Thus, it is concluded that the damaged life builds a relationship of resentment between the listeners and the music with pretensions of autonomy, which becomes dangerous in the face of the few training possibilities that remain in the contradictions.

Keywords: Resentment; Philosophy of Music; Formation; Critical Theory. 
"[...] El pensamiento que mata al deseo, su padre, se ve sorprendido por la venganza de la estupidez".

Adorno

\section{Introducción}

LA VIDA DAÑADA ESTÁ POR TODAS PARTES. No se refiere solamente a grupos sociales oprimidos, exiliados o violados que viven vidas claramente dańadas y bastante distantes de lo que se podría entender como una vida buena o una vida justa. Tampoco se refiere a grupos que viven sin acceso a lo que existe de más elaborado, sea en el campo de la ciencia, de los derechos humanos, de las producciones artísticas o de las novedades tecnológicas. La vida dańada se refiere al modo de vida vigente, en que se hizo imposible constituirse como sujeto autónomo; en que la libertad se confunde con la posibilidad de elección de productos y formas de consumo disponibles; a la vida falsamente vivida, impedida en sus mediaciones que podrían apuntar hacia un devenir de humanización. Se refiere a la vida hegemónica, en la que ni siquiera es posible establecer experiencias verdaderas, sea con personas, sea con los productos del trabajo humano. Así, la vida dañada remite la vida cotidiana de todos nosotros, radicalmente limitada y falseada. Es ante este diagnóstico que Adorno escribe la obra Mínima Moralia ${ }^{1}$ : reflexiones desde la vida dañada.

En el contexto de la vida actual, en la que tanto se queda un fantasma de la idea de libertad ilimitada cómo se siente en la carne la mentira de esa idea, no es sorprendente que se engendren dos movimientos íntimamente relacionados: el deseo de aquello que humaniza y siempre es prometido y jamás alcanzado y, al mismo tiempo, el rechazo despectivo, cínico e incluso violento de las posibilidades reales de conquista de alguna otra vida que pueda indicar la falsedad de ésta y, mínimamente, corresponder a la noción de una vida buena. A esa constelación de afectos que tanto envuelve el deseo como el rechazo, impregnado por el cultivo de rabia y

${ }^{1}$ Adorno, T. W.: Minima Moralia. Trad. Luiz Eduardo Bicca e Rev. Guido de Almeida. São Paulo: Editora Ática, 1993 (publicación original, 1951). 
rencor contra no-se-sabe-bien-que, llamaremos resentimiento. Con el avance de las sociedades modernas, con pretensiones libertarias y democráticas claramente contrariadas en las vivencias humanas marcadas por la exigencia de brutales sacrificios, cada vez más el resentimiento vive tiempos de fecundidad.

Tolerar el dolor y la frustración de la vida dañada no es sencillo, ya que son perceptibles, aunque no clara y conscientemente, las contradicciones del mundo vigente. A pesar de ser comúnmente dolorosa, la percepción de tales contradicciones es también una oportunidad importante de crítica, lo que hace que tal percepción sea forzosamente anestesiada por los sujetos y por las artimañas de adaptación y mantenimiento de esa sociedad. Los avances de la industria cultural $2.0^{2}$, por ejemplo, evidencian el investimento y la demanda de estímulos que mantengan a los sujetos en un estado de autoengaño controlado. Entre los productos de la industria cultural, la música merece la atención: ella llena casi ubicuamente los espacios sociales y eso cuando no es cargada por los sujetos en aparatos portátiles por los más variados ambientes y durante tiempo significativo. Tal vez sea posible afirmar que, si no todos tienen acceso a internet o no todos dediquen atención a la radio o a la televisión, todos escuchan música.

Producto del trabajo humano y mediado por la industria cultural, la música no se encuentra separada de la racionalidad que rige la vida dańada. Pero los sonidos, etéreos e impalpables, encantan, distraen y embellecen, decorando un mundo que impide las posibilidades de felicidad. Incluso un oyente que desconoce las señales del pentagrama y las reglas que articulan el sistema tonal, por ejemplo, es capaz de ser afectado por la ejecución de una obra musical, justamente porque la música se hace tanto de racionalidad como de encantamientos, en medios los más variados. Además, como producto cultural de una época, de una coyuntura social, la música nos comunica familiaridad o extrañeza y es así capaz de afectarnos. Reconocer una canción ya en sus primeros sonidos es lo que hace eclosionar aplausos de una audiencia; es lo que nos encamina para la apropiación de aquella canción, considerando afectivamente que aquella es "nuestra música"; es lo que evita que dejemos de oírla accionando el botón que nos encamina la canción siguiente.

Sin embargo, ¿qué sería capaz de provocarnos una música que desagrada, que "dice" lo que no deseamos oír, que apunta las contradicciones de la vida dañada y que tiene potencialidad para despertar a los oyentes de un estado de insensibilidad defensiva? La hipótesis aquí es que las canciones con pretensión de autonomía, que acogen las contradicciones y lo no idéntico y que, por lo tanto, tienen potencial de crítica y formación humana también afectan a los oyentes y provocan, a su vez,

2 Duarte, R. A. P.: Indústria cultural 2.0. Constelaciones - Revista de Teoría Crítica, no 3, dez. 2011, pp. 90 -117 
rechazo. Una negativa resentida, despectiva del potencial reflexivo y formativo de otra construcción musical; que busca desviar de la incomodidad y de los dolores que nos son tan familiares. De este modo, hasta una modesta posibilidad real de construcción de pensamiento para una vida otra, es rechazada, aunque sea lo que se desee. Discutir esta hipótesis es el objetivo de este trabajo.

\section{Vida dañada y resentimiento}

La vida social y Cultural, desde los principios del proceso civilizatorio, exigió a los sujetos sacrificios libidinales tanto en el sentido de aplazar y abstenerse de placeres como en el sentido de controlar impulsos agresivos que, al final, también pueden llevar a satisfacciones. El diagnóstico freudiano ya nos comunicó que ese proceso se desdobló en incómodos que son inherentes a las organizaciones sociales humanas ${ }^{3}$. Aunque se manifiesta de diferentes modos según épocas y organizaciones sociales, algún malestar es inherente a la vida social humana. Al actualizar el diagnóstico freudiano, Rouanet discute que las sociedades modernas producen una incomodidad que acaba de manifestarse como un "gran resentimiento contra la civilización" ${ }^{4}$. Tal resentimiento se dirigía entonces contra los principios que dieron el tono del proyecto Iluminista que, en síntesis, anheló una humanidad autónoma y emancipada a través de los poderes de la razón.

La constatación de una vida dañada que, en rigor, exige una ideología que "intenta engañarnos escondiendo el hecho de que no hay más vida" 5 evidencia que la vida autónoma vislumbrada por el proyecto Iluminista no está en vías de realizarse. No desistir de la propuesta de trabajar por una humanidad razonable, aunque sea una cuestión de supervivencia, no es el camino obvio y no excluye la realización de una importante crítica de la racionalidad. Más evidente, sin embargo, parece ser el cultivo de rencores de los vislumbres de autonomía y la búsqueda de compensación de los sacrificios que la civilización exigió, lo que caracteriza el contexto de la vida dañada como un combustible a la manifestación de una gama de afectos resentidos. El hecho de que la racionalidad occidental se haya constituido, en su forma hegemónica, como racionalidad instrumental - de ahí la urgencia de la necesidad de una crítica radical de la razón - amplifica la problemática de los afectos, ya que,

3 Freud, S.: O mal-estar na civilização. In. : Obras completas vol. 18. Trad. Paulo César de Souza. São Paulo: Companhia das Letras, 2010, pp. 13 - 122. (Publicación original 1930).

${ }^{4}$ Rounnet, S. P.: Mal-estar na modernidade. In. : Mal-estar na modernidade. Sáo Paulo: Companhia das Letras, pp. $96-119,1993$, p. 66.

5 Adorno, T. W.: Minima Moralia. op. cit. p. 7. 
en lugar de acogidos y comprendidos como aspectos inherentes a la racionalidad y al pensamiento, ellos son reprimidos como irracionalidad.

\section{Música, fetiche y resentimiento}

Un PRODUCTO DE LA CULTURA que, a pesar de las condiciones de la vida dañada, guarda al mismo tiempo potencial de promover tanto la servidumbre y la adecuación, como también la formación, el pensamiento y el vislumbre de una organización otra, es la música. Hegemónicamente mediada por la industria cultural, la música ocupa prácticamente todos los espacios cotidianos: se oye música en los establecimientos comerciales, en los restaurantes, en los gimnasios de gimnásticas, en los ascensores, dentro de los automóviles, en aparatos de sonido domésticos. Con potenciales mayores de elección, pero también radicalmente limitado en los potenciales de autonomía, también se oye música a través de auriculares mientras se realizan trayectos habituales por las calles, dentro de los transportes colectivos, durante actividades físicas y una amplia gama de otras actividades. Si bien este no es un público que abarrota las escuelas de música, ya que una formación cultural plena es justamente algo violentamente impedido en la configuración social vigente, esos oyentes son afectados por las propiedades de esas obras musicales.

Las posibilidades de ser afectados por una obra musical incluyen una íntima relación, que es inherente a las construcciones musicales, entre aspectos de racionalización técnica y matemática y aspectos de hechizo, encantamientos que pueden ser identificados como un fetichismo típico de la lógica mercancía, como en el concepto marxiano, pero que no se limitan a esa forma de fetichismo. Las propiedades sonoras de altura, timbre, ritmo y armonización de sonidos remiten a intentos ancestrales de afinación y de organización sonora, que implican un carácter cultural y político en la elección y ordenación de los sonidos. La construcción del sistema tonal, vigente actualmente mismo ya habiendo sido superado musical e históricamente, también remite a una larga historia de sistematización de alturas que pasa por la matemática pitagórica, incluye la diseminación, vía cruzadas, de las notaciones italianas y alcanza el temperamento acústico que se reconoce como agradable y correcto por el oyente contemporáneo ${ }^{6}$.

\footnotetext{
${ }^{6}$ Adorno, T. W.: O fetichismo na música e a regressão da audiçăo. In: Horkheimer e Adorno: Os Pensadores: Horkheimer e Adorno. Trad. Zeljko Loparic et. al. São Paulo: Nova Cultural, p.77- 105, 1991 (publicación original 1938); ADORNO, T. W.: Por que é difícil a nova música? In: Coнn, G. (org): Adorno - Sociologia. São Paulo: Ed. Ática, p. 147-161, 1986 (publicación original 1968); WEBER, M.: Os fundamentos racionais e sociológicos da música. Trad. de Leopoldo Waizbort. São Paulo: Edusp, 1995 (publicación original 1921); ATTALI, J.: Noise - The Political Economy of Music. Trad. Universidade de Minnesota. USA: Minnesota University Press,
} 
Considerando estas relaciones del oyente con las canciones, es de suponer que, a no ser en sentidos catárticos de manifestaciones irreflexivas de emociones, no se oye música para provocar el estrangulamiento de los dolores y las molestias humanas o de reflexionar sobre una vida que no es tan buena como podría ser. Es comprensible que las personas escuchen música para, por el contrario, distraerse y motivarse a la realización de las actividades cotidianas tantas veces carentes de sentido y de satisfacción. Cito aquí una autora que sintetiza ese diagnóstico:

En efecto, el espacio que se reservó para el arte en la cultura de masa bordea casi el "terapéutico". El ser humano contemporáneo, apartado de la naturaleza y subyugado por la razón tecnicizada, busca en el arte la realización de la identidad perdida. Sin embargo, la vanguardia estética se niega a ocupar ese lugar y la revuelta humana es tan violenta a medida que ve hasta la propia música, santuario último de la subjetividad de todas las demás expresiones artísticas, sucumbir a la expoliación afectiva emprendida por la técnica ${ }^{7}$.

La música que anhela la autonomía se atreve a frustrar al oyente y eso no es tolerado por él, que la rechaza, sea ante la exposición a los primeros sonidos, sea de antemano, acusándola de intelectualismo, elitismo o protegiéndose en el gusto: "No me gusta". Al mismo tiempo, la incomodidad producida por la vanguardia artística demuestra el poder crítico de la búsqueda de la autonomía sonora. Es en ese sentido que Adorno afirma que la pretensión de autonomía en la obra artística, su contenido de verdad, coincide con su contenido crítico $^{8}$. $\mathrm{Y}$ al mismo tiempo, en las palabras de Adorno, "la experiencia artística sólo es autónoma cuando se deshace del gusto de la fruición" ". Ahora, inmersos en la vida dañada, los oyentes tanto desean el devenir que puede ser vislumbrado en la experiencia artística autónoma cuanto rechazan el esfuerzo y la incomodidad que viene de esa experiencia. Para Adorno: "En el mundo falso toda $\eta \delta o v \eta$ [fruición] es falsa. Por lo tanto, el deseo sobrevive en el arte" ${ }^{10}$. La profundización de la reflexión y de las contradicciones manifiestas en las posturas resentidas son, por esas ambigüedades, espacios fecundos de crítica. El fetiche que permanece expresado en las canciones por la constitución inherentemente impalpable de esta, es capaz de hacer recordar a los seres humanos

2003 (publicación original 1977); WISNIK, J. M.: O som e o sentido. São Paulo: Ed. Companhia das Letras, 2006 (publicación original 1989).

7 Arzua, G.: Reificação e autonomia: a dupla face da razão na estética musical de Adorno. In. Ramos-de-Oliveira, N. Zuin, A. A. S. e Pucci, B. (orgs): Teoria crítica, estética e educação. Campinas: Autores Associados; Piracicaba: Ed. Unimep, pp. 175 - 184, 2001, p. 178.

${ }^{8}$ Adorno, T. W.: Teoria Estética. Trad. Artur Morão. Coimbra/Portugal: Ediçôes 70, 2011 (publicación original 1970).

${ }^{9}$ Ibid. p. 28

${ }^{10}$ Ibid., p. 29 
aspectos violentamente reprimidos y recalcados por la exclusión de la naturaleza en el proceso de desencanto del mundo. Esta naturaleza vislumbrada en las canciones tanto es capaz de atraer como es capaz de aterrorizar y provocar rechazo. Si el resentimiento típico de la modernidad se dirige contra el proyecto iluminista y contra la civilización de un modo general, también se dirige contra las obras musicales que acogen las contradicciones que el proceso civilizatorio violentamente buscó extirpar. Citando a Adorno:

La ira contra la vanguardia es tan desmedida y sobrepasa tanto su función real en la sociedad industrial tardía y, también, excede demasiado su participación en las ostentaciones culturales de esta sociedad, sólo porque la conciencia angustiada encuentra, en el arte nuevo, cerradas las puertas a través de las cuales esperaba escapar a la Aufklärung total, porque hoy el arte, al menos el arte realmente sustancial, refleja sin concesiones y lanza a la superficie todo lo que se quería olvidar ${ }^{11}$.

El arte nuevo o la música nueva a la que Adorno se refiere en la obra Filosofía de la nueva música ${ }^{12}$ ya completó más de cien ańos y no fue capturada ni siquiera por la implacabilidad de la industria cultural. Al no configurarse como cómplice de la falsa armonía entre lo universal y lo particular, al revés del sistema tonal qué lo hace con maestría a punto de configurarse como una segunda naturaleza para el oído moderno, la música de vanguardia es molesta. Pero esa recepción despectiva y eventualmente violenta no puede ser comprendida en el marco del "gusto" o de la carencia formativa individual, recortándose el individuo de una configuración que remite a la vida dańada y a los impedimentos formativos que a su vez también constituyen subjetividades, aunque deseosas, que rechazan lo que aún queda de espacio formativo.

\section{Por una crítica de la racionalidad}

LA SEPARACIÓN VIOLENTA ENTRE ESPÍRITU Y MATERIA es antigua y el desarrollo de la racionalidad instrumental evidencia esta dicotomía brutalmente. Las manifestaciones afectivas son condenadas a la irracionalidad y tratadas con frialdad, siendo toleradas en espacios donde existe una cierta administración de la catarsis. Las dicotomías que se expresan en el rechazo de la razón instrumental en acoger el

\footnotetext{
${ }^{11}$ ADORNO, T. W.: Filosofia da Nova Música. Trad. Magda França. São Paulo: Ed. Perspectiva, 2009 (publicación original 1958), p. 21.

12 Ibid.
} 
movimiento y la contradicción se constituyen tanto como impedimentos a la humanización y una amenaza latente de retorno a la barbarie, cuanto constituyen posibilidades de confrontación y, por la profundización de la contradicción, posibilidades de superación de la condición vigente.

Al discutir sobre los afectos y la racionalidad vigente y, al mismo tiempo, sobre la música, que en su configuración intrínseca es una manifestación de otra racionalidad, hay que tratar con las más antiguas separaciones que nos siguen provocando tanto miedo como atracción. La elaboración de esos aspectos violentamente reprimidos de la cultura es imprescindible para que se mire más allá la condición de una vida dañada. Además, ante el peso de la organización vigente para la adaptación, hay que tener en cuenta cuánto las subjetividades humanas están forjadas para, aunque eso cueste un penoso sufrimiento, mimetizar los aspectos deshumanizadores de la cultura para así integrarse a ella. Reflexionar sobre aspectos afectivos y de la racionalidad vigente y pensar sobre posibilidades de elaboración requiere que esas cuestiones sean ampliamente exploradas.

Esta condición, expresada por la vida dañada y por las subjetividades forjadas desde la más tierna edad para la adecuación y la integración a esa vida, señala el avance de la contradicción apuntada hace tiempo por Adorno y Horkheimer ${ }^{13}$, al final, en la búsqueda de una racionalidad apartada de cualquier vestigio de su presumido opuesto, la humanidad viene siendo lanzada a un camino pautado por la irracionalidad. No se trata, sin embargo, de resignarse a ese desarrollo de las cosas, pero se trata de resistir a la integración total de las subjetividades a los modos inhumanos de organización social en lo que sea posible y, apostando por el potencial crítico de la acogida de las contradicciones, evidenciar que el modo como la vida dañada se organiza no es absolutamente inevitable. La simplicidad de esta formulación parece ser también la señal de su más aguda dificultad.

\section{Apuntes concluyentes}

Pensar el resentimiento en relación a la cultura de un modo general y en relación a la sensibilidad cognoscitiva exigida por las producciones artísticas, especialmente en el caso peculiar de la música, lleva a la luz ambigüedades importantes para fomentar la resistencia de los sujetos, cada vez más impedidos en sus posibilidades de desarrollar una individualidad autónoma frente a la radicalización de la

${ }^{13}$ ADORnO, T. W. e HORKHEIMER, M.: Dialética do Esclarecimento. Trad. Guido Antônio de Almeida. Rio de Janeiro: Ed. Zahar, 2006 (publicación original 1944). 
vida dañada. Las dicotomías pavor y deseo, cultura y naturaleza, mente y cuerpo, resultados del largo proceso de desencanto del mundo, necesitan ser exploradas en su potencial crítico y elaboradas en el sentido de apuntar posibilidades de una vida más humanizada. Esta elaboración nos aparece tan urgente como delicada y demanda esfuerzos de las más variadas ciencias. Sin embargo, trabajar en el sentido de una racionalidad que supere esas dicotomías es necesario para que se vislumbre una vida más humana. El esfuerzo necesario para mantener las cosas como son no puede ser menospreciado, pero al mismo tiempo, confrontarlo parece ser imprescindible para que se vislumbre potencialmente aquello que, después de todo, se desea: una vida en que las posibilidades de felicidad correspondan verdaderamente a las necesidades y a las posibilidades de la técnica y de la ciencia. 


\section{ReferenCias Bibliográficas}

Adorno, T. W.: "O fetichismo na música e a regressão da audição". In: Horkheimer e Adorno: Os Pensadores: Horkheimer e Adorno. Trad. Zeljko Loparic et. al. São Paulo: Nova Cultural, pp. 77- 105, 1991 (publicación original 1938).

- Minima Moralia. Trad. Luiz Eduardo Bicca e Rev. Guido de Almeida. São Paulo: Editora Ática, 1993 (publicación original, 1951).

- Filosofia da Nova Música. Trad. Magda França. São Paulo: Ed. Perspectiva, 2009 (publicación original 1958).

- "Por que é difícil a nova música? ” In: Cohn, G. (org): Adorno - Sociologia. São Paulo: Ed. Ática, pp. 147-161, 1986 (publicación original 1968).

- Teoria Estética. Trad. Artur Morão. Coimbra/Portugal: Edições 70, 2011 (publicación original 1970).

Adorno, T. W. e Horkheimer, M.: Dialética do Esclarecimento. Trad. Guido Antônio de Almeida. Rio de Janeiro: Ed. Zahar, 2006 (publicación original 1944).

ArzuA, G.: "Reificação e autonomia: a dupla face da razão na estética musical de Adorno". In. Ramos-de-Oliveira, N. Zuin, A. A. S. e Pucci, B. (org.): Teoria crítica, estética e educação. Campinas: Autores Associados; Piracicaba: Ed. Unimep, pp. 175 - 184, 2001.

Attali, J.: Noise - The Political Economy of Music. Trad. Universidad de Minnesota. USA: Minnesota University Press, 2003 (publicación original 1977).

Duarte, R. A. P.: "Indústria cultural 2.0". Constelaciones - Revista de Teoría Crítica, no 3, dez. 2011, pp. 90 -117. Enlace: http://constelaciones-rtc.net/article/view/750/804

Freud, S.: "O mal-estar na civilização". In. : Obras completas vol. 18. Trad. Paulo César de Souza. São Paulo: Companhia das Letras, 2010, pp. 13 - 122. (Publicación original 1930).

RouAnet, S. P.: "Mal-estar na modernidade". In. dernidade. São Paulo: Companhia das Letras, pp. $\overline{96-119,1993 .}$

Weber, M.: Os fundamentos racionais e sociológicos da música. Trad. Leopoldo Waizbort. São Paulo: Edusp, 1995 (publicación original 1921).

Wisnik, J. M.: O som e o sentido. São Paulo: Ed. Companhia das Letras, 2006 (publicación original 1989).

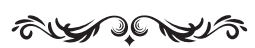

DOI: http://doi.org/10.15366/bp2019.21.008

Bajo Palabra. II Época. No21. Pgs: 147-158 
